TITLE:

\title{
Variation in herbivory-induced responses within successively flushing Quercus serrata seedlings under different nutrient conditions
}

\section{AUTHOR(S):}

Mizumachi, Eri; Mori, Akira S.; Akiyama, Reiko;

Tokuchi, Naoko; Osawa, Naoya

\section{CITATION:}

Mizumachi, Eri ... [et al]. Variation in herbivory-induced responses within successively flushing Quercus serrata seedlings under different nutrient conditions. Journal of Forest Research 2012, 17(2): 175-183

\section{ISSUE DATE:}

2012-04

URL:

http://hdl.handle.net/2433/155044

\section{RIGHT:}

The final publication is available at www.springerlink.com; この論文は 出版社版でありません。引用の際には出版社版をご確認ご利用くださ $\omega_{\circ}$; This is not the published version. Please cite only the published version. 
1 Title: Variation in herbivory-induced responses within successively flushing

2 Quercus serrata seedlings under different nutrient conditions

3

4 Authors: Eri Mizumachi ${ }^{1,2}$, Akira S. Mori ${ }^{1,3}$, Reiko Akiyama ${ }^{1,4}$, Naoko Tokuchi ${ }^{5}$, Naoya

5 Osawa $^{1}$

6

71 Division of Environmental Science and Technology, Graduate School of Agriculture, Kyoto

8 University

92 (present address) Institute for Integrated Cell-Material Sciences (iCeMS), Kyoto University

103 (present address) Graduate School of Environment and Information Sciences, Yokohama

$11 \quad$ National University

124 (present address) Department of Plant Ecology and Evolution, Evolutionary Biology Centre

13 (EBC), Uppsala University

145 Field Science Education and Research Center, Kyoto University

15 Corresponding Author: Eri Mizumachi

16 Science Communication Group, Institute for Integrated Cell-Material Sciences (iCeMS),

17 Kyoto University, Yoshida Ushinomiya-cho, Sakyo-ku, Kyoto 606-8501, Japan

18 Tel: +81-75-753-978 / Fax: +81-75-753-9785 / Email: emizumachi@icems.kyoto-u.ac.jp

19 Article type: Original article, Subject area and fields: Biology and ecology

20 Page count for text: 37 pages, Number of Tables: 1, Number of Figures: 5 
21 Abstract Herbivore damage can induce the host plant to alter the chemical and physical

22 quality of its leaves, which is thought to be a plant strategy for avoiding further herbivory,

23 termed induced response. In woody plants, many studies have considered variation in induced

24 responses with resource availability, but few studies have examined this variation in relation to

25 growth patterns of woody plants. We studied phenotypic variability of induced response within

26 successively flushing Quercus serrata seedlings. Q. serrata seedlings were grown under

27 controlled conditions. The controlled factors were herbivore damage (herbivore-damaged and

28 -undamaged) and soil fertility (low and high). At each flush stage, concentrations of condensed

29 tannin $(\mathrm{CT})$, total phenolics $(\mathrm{TP})$, and nitrogen $(\mathrm{N})$ in leaves were analysed and leaf mass per

30 area (LMA) was measured. CT and TP concentration of leaves and LMA were higher in

31 herbivore-damaged seedlings. Leaves of the first flushes showed greater sensitivity to herbivore

32 damage and had a higher CT concentration than leaves of the later flushes. Furthermore,

33 seedlings growing in low-fertility soil showed greater induced response. The results suggest that

34 Q. serrata seedlings showed induced response related to contributions of the tissue to current

35 productivity. Leaves of the first flush showed greater induced response possibly because they

36 play an important role in subsequent growth. The potential of Q. serrata seedlings to adjust the

37 properties of leaves depending on herbivory and soil fertility in relation to growth patterns may

38 be advantageous in forest floor where seedlings grow in heterogeneous soil fertility and are

39 constantly exposed to herbivory.

40

41 Keywords: Herbivorous insect, Induced response, Oak, Phenolics, Leaf flushing, Soil fertility 


\section{Introduction}

43

44 Leaf quality of host plants is an important property for herbivores in choosing their food

45 (e.g., Mattson 1980; Nykänen and Koricheva 2004). Leaves with high nitrogen (N)

46 concentration have been positively related to insect feeding and performance (Wait et al. 1998;

47 Lower et al. 2003). Concentrations of nitrogen and phenolic compounds within leaves are major

48 determinants of distribution and abundance of herbivores (e.g., Kytö et al. 1996; Lill and

49 Marquis 2001; Murakami et al. 2005). For example, condensed tannin (CT) and total phenolics

50 (TP) have negative effects on the growth and survival of insects (e.g., Mutikainen et al. 2000;

51 Lill and Marquis 2001; Nomura and Itioka 2002). Leaf mass per area (LMA) and leaf toughness

52 are often used as indices of leaf physical defences (e.g., Feeny 1970; Kudo 1996; Nabeshima et

53 al. 2001) and may vary in relation to leaf chemical properties (Poorter et al. 2009). Furthermore,

54 LMA and leaf toughness are recognised as important deterrents to herbivory (Coley 1983; Reich

55 et al. 1991; Choong 1996, Hanley et al. 2007).

56 Conversely, herbivores can affect the quality of damaged leaves and leaves produced after

57 implementation of the damage (e.g., Karban and Myers 1989; Karban and Baldwin 1997). 
58 Consequently, in a seasonal environment, leaf damage early in the growth season affects the

59 distribution and abundance of herbivores, which, in turn, causes changes in leaf quality later in

60 the growth season (Hunter 1987; Wold and Marquis 1997; Boege 2004). These changes in leaf

61 quality caused by herbivory thus seem to be one of important plant strategies for avoiding

62 additional herbivore damage; this strategy is termed "induced response" (e.g., Karban and

63 Myers 1989; Karban and Baldwin 1997).

64 Induced response varies with environmental factors such as the availability of nutrients,

65 light and water (e.g., Hunter and Schultz 1995; Mutikainen et al. 2000; Nabeshima et al. 2001;

66 Baraza et al. 2004). The pattern of carbon allocation toward induced response depends not only

67 on the external availability of resources, but also on the internal characteristics of the plant

68 (Nykänen and Koricheva 2004). Nykänen and Koricheva (2004) conducted a meta-analysis of

6968 studies, and showed that the plant responses induced by herbivory depend on plant type

70 (evergreen or deciduous) and inherent growth rate; phenolic compounds of leaves increase

71 following damage in deciduous and fast-growing species, but not in evergreen or slow-growing

72 species. Therefore, in clarifying induced response in woody species, it is important to take into

73 consideration the variations in leaf quality within plant. 
and the abundance and performance of herbivorous insects (e.g., Feeny 1970; Rossiter et al.

1988; Hunter and Schultz 1995; Forkner et al. 2004). In Japan, Quercus species, including $Q$.

serrata, are important components of deciduous temperate forests (Ozawa et al. 2000; Ohsawa

et al. 2008) and have been the subject of understanding interactions between plants and

herbivores. Large numbers of herbivorous insects, such as Lepidopterans use Q. serrata as a

host plant (Teramoto 1993; Teramoto 1996). The extent of leaf damage by herbivorous insects

81 in Quercus species changes temporally among years (Furuno and Saito 1981) and spatially

82 among branches, even within the same individual (Yamasaki and Kikuzawa 2003; Nakamura et

83 al. 2008). Like other woody plants, Quercus species could respond to the temporal and spatial

84 fluctuations in herbivore damage because they have semi-autonomously modular units (Watson

85 1986; Sprugel et al. 1991). Quercus seedlings growing in forest floor may respond especially

86 well to severe herbivore damage by adjusting the pattern of leaf flushing because they are constantly exposed to insect attacks during most of growing season. 
90 show several growth flushes within a growing season (e.g., Borchert 1975; Charr et al. 1997a, b).

91 We previously demonstrated that herbivore damage increased both the total number of flushes

92 and the probability of producing a later flush in Q. serrata seedlings (Mizumachi et al. 2004,

93 2006). Our previous studies also showed that the probability of flushing was prominent in

94 seedlings grown in high-fertility soil than ones grown in low-fertility soil (Mizumachi et al. 2004,

95 2006). While these studies demonstrated the nutrient level dependent effect of herbivory on the

96 pattern of flushing, induced response to herbivory at different nutrient levels in Q. serrata

97 remains to be known. Here, we investigated phenotypic variability of induced response within $Q$.

98 serrata seedlings. We examined whether herbivory induces change in chemical and physical

99 properties of leaves in different flushes, and whether the response varies depending on the soil

100 fertility. The results will be discussed in relation to the growth pattern under different soil

101 nutrient availability. 
Plant materials

106

We used a group of 120 Quercus serrata Thunb. Ex Murray seedlings purchased from

the Kutsuki Village Forest Association (Shiga Prefecture, Japan) in December 2001. These

seedlings had been grown in uniform environment prior to the experiment. The roots of each

110 seedling were washed to remove any remnants of soil, and then all seedlings were transplanted

111 into plastic pots (44 cm in diameter, $24 \mathrm{~cm}$ in depth) with $500 \mathrm{ml}$ of kanuma soil (pumice) at the

112 bottom and filled with sand. The mean seedling height at the start of the experiment was $43.4 \pm$

$1130.4 \mathrm{~cm}($ mean $\pm \mathrm{SE})$. Seedling height did not differ significantly among the treatments (Scheffe's

114 range test, $\mathrm{P}>0.05$ ). All seedlings were watered to saturation for $10 \mathrm{~min}$ daily by an automatic

115 sprinkler (Sprinkler Thinker DC-1, Irrigation Control Equipment, Galcon ${ }^{\circledR}$ ).

116 In early April 2002, the winter buds of Q. serrata seedlings were beginning to unfold

117 (defined as 'first flush'). These shoots that elongated from the winter buds were termed 'the first

118 shoots'. During the growth season, most of the seedlings had more than one flush. The shoots

119 formed after the first flush were considered 'the second shoots', and the following shoots were

120 'the third shoots' and 'the fourth shoots'. These flushes and shoots emerging after the first flush 
121 were defined as 'later flush' and 'later shoots', respectively. Bud-break of the last flush occurred

122 in early October 2002. Because a two-dimensional diagram was drawn to illustrate the

123 branching structure of each seedling when new shoots elongated during the growing season, we

124 could identify when each shoot elongated. Maximum number of flushes was five among all

125 seedlings and four among seedlings sampled.

127 Experimental design

128

The study was carried out at Kitashirakawa Experimental Station of Kyoto University in

130 Kyoto, Japan $\left(35.02^{\circ} \mathrm{N}, 135.47^{\circ} \mathrm{E}\right)$. The average annual temperature at the station is $15.9^{\circ} \mathrm{C}$

131 (Field Science Education and Research Center, Kyoto University). Quercus serrata is found

132 naturally distributed around the experimental station. Seedlings were grown in two greenhouses

$133(\mathrm{H} 1,10 \times 7.5 \mathrm{~m}, 4 \mathrm{~m}$ in height; $\mathrm{H} 2,9.5 \times 4.4 \mathrm{~m}, 3.5 \mathrm{~m}$ in height). These greenhouses were

134 located on the same site with no obvious difference in environmental conditions and the distance

135 between two greenhouses was within $25 \mathrm{~m}$. Therefore, we have treated the data of the

136 greenhouses equally for analyses. The roofs were made of transparent plastic. The sides were 
137 constructed using nylon mesh to allow free air circulation. In this experiment, we manipulated

138 herbivore damage and soil fertility, but we did not manipulate temperature and light conditions

139 in the greenhouses.

140 We controlled the herbivore damage by size of nylon mesh. The sides of the

141 herbivory-undamaged blocks were made of $1 \times 1 \mathrm{~mm}$ nylon mesh. This mesh size effectively

142 reduced herbivore damage (the leaf area loss in herbivore-undamaged blocks were less than 3\%).

143 Because a few insect invasions did occur, we checked all seedlings and removed invasive

144 insects from the herbivory-undamaged blocks every 2 days. On the other hand, those in the

145 herbivory-damaged blocks were made of $20 \times 20-\mathrm{mm}$ mesh to allow insect herbivores free

146 access. Quercus serrata and other Quercus species (e.g. Q. glauca and Q. acutissima)

147 are growing also outside the greenhouses. Therefore we can regard that the seedlings in

148 these blocks were damaged naturally by insect herbivores.

149 Leaf damage within this experimental system was caused mainly by the following

150 generalist herbivorous insects: larvae of Lepidoptera belonging to the families Oecophoridae,

151 Lecithoceridae, Noctuidae, Geometridae, Lymantriidae, and Arctiidae; larvae of Hymenoptera

152 belonging to the family Tenthredinidae; and adults of Coleoptera belonging to the families 
153 Attelabidae and Scarabaeidae (Ishii H and Osawa N, unpublished data).

154 Seedlings in each block were randomly assigned to fertilisation treatments (low- and

155 high-soil fertility) with the application of 25:5:20 NPK fertiliser (Peters Professional,

156 HYPONeX JAPAN ${ }^{\circledR}$ ) every 2 weeks from April to November 2002. The concentration of

157 fertiliser was adjusted to obtain two levels of soil fertility. Half of the seedlings in each block

158 were grown under low soil fertility $\left(20 \mathrm{~kg} \mathrm{~N} \mathrm{ha}^{-1} \mathrm{year}^{-1}\right)$; the other half grew under high soil

159 fertility $\left(200 \mathrm{~kg} \mathrm{~N} \mathrm{ha}^{-1}\right.$ year $\left.^{-1}\right)$.

160

161

162 Plant measurements

163

A two-dimensional diagram was drawn to illustrate the branching structure of each

sapling when new shoots elongated during the growing season. For each shoot, all leaves were

166 roughly categorized into one of seven classes based on leaf damage, which was determined

167 visually by estimating the percentage of leaf area loss: $0 \%$, damage class $0 ; 1-5 \%$, damage class

$1681 ; 6-25 \%$, damage class $2 ; 26-50 \%$, damage class $3 ; 51-75 \%$, damage class $4 ; 76-99 \%$,

169 damage class $5 ; 100 \%$, damage class 6 . The assessment of leaf damage class was done when 
170 each shoot has stopped elongating and the leaves have just fully unfolded. Leaf damage for each

171 shoot was calculated as an average value of these damage classes.

173 in total) for analysing chemical and physical properties of leaves. The experimental system was

174 planned for continuous research; therefore, we sampled a minimum number of seedlings. The

175 leaves of each flush within sampled seedlings were photocopied separately. The images were

176 scanned and then processed with an image analysis program (NIH image ver. 1.63, National

177 Institutes of Health, MD, USA) to obtain leaf area of each shoot. After photocopying, the

178 leaves were oven-dried at $70^{\circ} \mathrm{C}$ for $2 \mathrm{~d}$. Dry mass of leaves was measured to determine the leaf

179 mass per area (LMA). Dried leaves were ground into fine powder with a mill (TI-100, CMT CO.

180 LTD., Tokyo, Japan). The nitrogen (N) concentration was determined by gas

181 chromatography with an NC analyser (SUMIGRAPH, NC-900, SUMIKA Chemical

182 Analysis Service, LTD., Tokyo, Japan). The shoots analysed were: (1) the first shoots (120 for

183 LMA, and 100 for N), (2) the second shoots (50 for LMA, 36 for N), and (3) the third and fourth

184 shoots (43 for LMA, 33 for $\mathrm{N}$ ). The nitrogen analysis required at least $20 \mathrm{mg}$ of dried leaf, and

185 therefore we could not analyse several small shoots. 
187 five first shoots for analyses of condensed tannin (hereafter CT) and total phenolics (hereafter

188 TP). Because several shoots yielded small amount of leaves for chemical analyses, we could not

189 analyse all selected shoots. The categories of shoots analysed included (1) the first shoots (53 for,

190 CT and 56 for TP), (2) the second shoots (27 for CT, 27 for TP), and (3) the third and fourth

191 shoots (22 for CT, 23 for TP). The sample leaf powders were extracted with $50 \%$ methanol for

$19224 \mathrm{~h}$. The concentration of CT was quantified with a spectrophotometer (UV-1200,

193 SHIMADZU, Kyoto, Japan), using cyaniding chloride as a standard (Porter et al. 1986). The

194 concentration of TP was quantified with a spectrophotometer (U-1000, HITACHI,

195 Tokyo, Japan), using tannic acid as a standard (Waterman and Mole 1994). Phenolic

196 compounds, such as CT and TP, in leaves have been commonly used as indicators of chemical

197 defence against herbivores (e.g., Feeny 1970; Forkner and Hunter 2000; Mutikainen et al. 2000;

198 Nabeshima et al. 2001; Forkner and Marquis 2004; Matsuki et al. 2004; Murakami et al. 2005;

199 Koike et al. 2006).

As a preliminary analysis of initial properties of selected seedlings, we compared the

201 lengths of the first shoots among sampled seedlings within each treatment. A one-way analysis 
of variance (ANOVA) revealed no noticeable differences among individuals within the

203 same treatment (one-way ANOVA, herbivory-damaged under low soil fertility, $F_{2,12}=0.500$,

$204 P=0.619$; , herbivory-undamaged in low-fertility soil, $F_{2,12}=1.619, P=0.239$;

205 herbivory-undamaged under high soil fertility, $F_{2,10}=2.071, P=0.177$ ), except for one

206 treatment (herbivory-damaged in high-fertility soil, $F_{2,12}=9.724, P=0.003$ ). In this treatment,

207 several first shoots were eaten by insect herbivores before elongation finished, and the difference

208 among individuals is thus likely to reflect the damage by herbivory rather than intrinsic variation

209 among the seedlings. Accordingly, we analysed the data without distinction among individuals

210 within each treatment.

212 Statistical analysis

214 For each flush stage, differences in leaf qualities were tested using a two-way ANOVA

215 with two between-subject factors (herbivore damage and soil fertility). However, the third and

216 the fourth shoots were tested together, because the harvested seedlings had few flush-stage

217 shoots. When a significant interaction was detected between herbivore damage and soil nutrient

218 fertility, Tukey's HSD test was performed for comparisons among the four treatments. 
219 For each treatment, differences in CT concentration and LMA between the periods of

220 shoot production (the first shoots and the later shoots) were tested using Student's $t$-test. CT

221 concentration and LMA scarcely decreased as the season progressed, while $\mathrm{N}$ concentration and

222 TP concentration were unstable over the growing season (Salminen et al. 2004; Migita et al.

223 2007). For this reason, we did not make comparisons of $\mathrm{N}$ concentration and TP concentration

224 in leaves between periods of shoot production.

225 The leaf damage of each flush-stage was analysed with Wilcoxon rank sum test under

226 low and high soil fertility. All statistical analyses were performed with JMP ver. 6.0 software

227 (SAS Institute 2005).

228

229 Results

230

231 Condensed tannin concentration

condensed tannin (CT) concentration were significant (two-way ANOVA, herbivore damage, $F$ 
$2351,49=35.712, P<0.0001$; soil fertility $\left.F_{1,49}=15.276, P=0.0003\right)$. The CT concentration was

236 significantly higher in herbivore-damaged seedlings than in undamaged seedlings, and

237 was significantly higher in seedlings in low-fertility soil than in high-fertility soil (Fig.

238 1). There was no significant interaction between herbivore damage and soil fertility

239 (two-way ANOVA, $F_{1,49}=0.314, P=0.578$, Fig. 1). For leaves of the second shoots,

240 the effects of herbivore damage on CT concentration were significant (two-way

241 ANOVA, $\left.F_{1,23}=10.272, P=0.004\right)$. The CT concentration was significantly higher in

242 herbivore-damaged seedlings than in undamaged seedlings (Fig. 1). The effects of soil

243 fertility on CT concentration were not significant (two-way ANOVA, $F_{1,23}=0.024, P=$

244 0.878, Fig. 1). There was no significant interaction between herbivore damage and soil

245 fertility (two-way ANOVA, $F_{1,23}=0.155, P=0.697$, Fig. 1). For leaves of the third

246 and fourth shoots, CT concentration did not differ among the four treatments (two-way

247 ANOVA, $F_{1,18}=2.862, P=0.066$, Fig. 1$)$.

248 In herbivore-undamaged seedlings in high-fertility soil, the CT concentration of leaves

249 was not significantly different between flush periods (Table 1). In the other treatments, CT

250 concentration of leaves in the first shoots was higher than in the later shoots (Table 1). 
252 Total phenolics concentration

253

For leaves of the first shoots, the effects of herbivore damage and soil fertility on the total

255 phenolics (TP) concentration were significant (two-way ANOVA, herbivore damage, $F_{1,52}=$

$2564.800, P=0.033$; soil fertility, $\left.F_{1,52}=24.909, P<0.0001\right)$. The TP concentration was

257 significantly higher in herbivore-damaged seedlings than in undamaged seedlings, and

258 was significantly higher in seedlings in low-fertility soil than in high-fertility soil (Fig.

259 2). There was no significant interaction between herbivore damage and soil fertility

260 (two-way ANOVA, $F_{1,52}=0.188, P=0.667$, Fig. 2). For leaves of the second shoots,

261 TP concentration was not significantly different among treatments (two-way ANOVA, $F$

$2621,23=1.850, P=0.166$, Fig. 2). For leaves of the third and fourth shoots, effects of soil

263 fertility on TP concentration were significant (two-way ANOVA, $F_{1,19}=14.415, P=$

264 0.001); the TP concentration in seedlings in low-fertility soil was significantly higher

265 than in high-fertility soil (Fig. 2). The effects of herbivore damage on TP concentration

266 were not significant (two-way ANOVA, $F_{1,19}=3.129, P=0.093$, Fig. 2). There was 
ANOVA, $F_{1,19}=0.265, P=0.613$, Fig. 2 ).

Leaf mass per area

and soil fertility (two-way ANOVA, $F_{1,116}=15.751, P=0.0001$, Fig. 3 ). The LMA in

274 herbivore-damaged seedlings was significantly higher than in undamaged seedlings,

especially in low-fertility soil (Fig. 3). For leaves of the second shoots, effects of

276 herbivore damage on LMA were significant (two-way ANOVA, $F_{1,46}=34.245, P<$

277 0.0001); the LMA in herbivore-damaged seedlings was significantly higher than in

278 undamaged seedlings (Fig. 3). However, the effects of soil fertility on LMA were not

significant (two-way ANOVA, $F_{1,46}=0.014, P=0.908$, Fig. 3). There was no

280 significant interaction between herbivore damage and soil fertility (two-way ANOVA,

$281 F_{1,46}=3.691, P=0.061$, Fig. 3). For leaves of the third and fourth shoots, there was

282 significant interaction between herbivore damage and soil fertility (two-way ANOVA, 
$283 F_{1,39}=9.047, P=0.005$, Fig. 3); the LMA in herbivore-damaged seedlings was

284 significantly higher than in undamaged seedlings, especially under low-fertility soil

285 conditions (Fig. 3).

In herbivore-damaged seedlings in low-fertility soil, LMA in the later shoots was

287 greater than in the first shoots (Table 1). In the other treatments, LMA was not

288 significantly different between flush periods (Table 1).

290 Nitrogen concentration

293 were significant (two-way ANOVA, $F_{1,96}=61.974, P<0.0001$ ). The $\mathrm{N}$ concentration of

294 seedlings in high-fertility soil was significantly higher than in low-fertility soil (Fig. 4),

295 but the effects of herbivore damage on the $\mathrm{N}$ concentration were not significant

296 (two-way ANOVA, $F_{1,96}=1.931, P=0.168$, Fig. 4). There was no significant

297 interaction between herbivore damage and soil fertility (two-way ANOVA, $F_{1,96}=$

$2982.747, P=0.101$, Fig. 4). For leaves of the second shoots, the $\mathrm{N}$ concentration was not 
significantly different among treatments (two-way ANOVA, $F_{1,32}=2.121, P=0.117$,

300 Fig. 4). For the leaves of the third and fourth shoots, the effects of soil fertility on $\mathrm{N}$

301 concentration were significant (two-way ANOVA, $F_{1,29}=18.001, P=0.0002$ ). The N

302 concentration in high-fertility soil seedlings was significantly greater than in

303 low-fertility soil seedlings (Fig. 4). The effects of herbivore damage on the $\mathrm{N}$

304 concentration were not significant (two-way ANOVA, $F_{1,29}=0.239, P=0.629$, Fig. 4).

305 There was no significant interaction between herbivore damage and soil fertility

306 (two-way ANOVA, $F_{1,29}=0.524, P=0.475$, Fig. 4 ).

307

308 Leaf damage

309

310 The leaf damage of the second shoots in high-fertility soil was significantly higher than in

311 low-fertility soil (Wilcoxon rank sum test, $P=0.1566$, Fig. 5). While, soil fertility did not

312 affect the leaf damage of the first, third, forth or fifth shoots (Wilcoxon rank sum test, first shoot,

$313 P=0.0099$; third shoot, $P=0.0577$; forth shoot, $P=0.1445$, fifth shoot, $P=0.7582$, Fig. 5). 


\section{Discussion}

317 The effect of insect damage on leaf quality at each flush stage

319 The increase in phenolic compounds in leaves of the herbivore-damaged seedlings and

320 the increase in LMA in every flush stage of Quercus serrata seedlings in this study can be

321 regarded as induced resistance against insect damage. Leaf damage by herbivorous insects

322 increased the condensed tannin (CT) concentration of leaves of the first and the second shoots,

323 and also increased the total phenolics (TP) concentrations of leaves of the first shoots (Figs. 1

324 and 2). Similar to our findings, the increases in CT and TP concentrations induced by herbivores

325 have been previously described (Haukioja 1990; Karban and Baldwin 1997; Nykänen and

326 Koricheva 2004). Increases in these phenolic compounds in leaves of a certain flush

327 stage can be interpreted as defensive reactions against further herbivory. Moreover, in

328 our study, leaf damage by herbivorous insects significantly increased the LMA in

329 every flush stage, especially when seedlings were grown in soil with low fertility (Fig.

330 3). This suggests that the increase in LMA is a response to the herbivore attacks. Our

331 result is related to findings of a previous study that showed a negative correlation 
332 between LMA and defoliation by herbivores within a crown of Fagus crenata

333 (Yamasaki and Kikuzawa 2003).

334 We showed for Q. serrata seedlings that $\mathrm{N}$ concentration of damaged leaves did not differ

335 from that in intact leaves (Fig. 4). In contrast, Kudo (1996) reported that nitrogen (N)

336 concentration of leaves of $Q$. crispula decreased following artificial damage. The differences in

$337 \mathrm{~N}$ concentration between damaged leaves and intact leaves were explained by differences in $\mathrm{N}$

338 allocation to leaves in mid-summer; $\mathrm{N}$ was not allocated to damaged leaves in mid-summer,

339 although it was allocated to intact leaves in the same season (Kudo 1996). On the other hand, the

340 discrepancy between the results for $Q$. serrata and $Q$. crispula might be caused by

341 species-specific differences in regrowth processes between the two plants. Quercus serrata

342 seedlings produced later shoots in mid-summer (Mizumachi et al. 2004, 2006); as a result, the N,

343 which was expected to be allocated to intact leaves in mid-summer, was distributed to the later

344 shoots.

345

346 Variability of induced responses 
The CT concentration varied among different flush stages, while no such

349 difference was detected for TP concentration. The CT concentration of leaves in the first

350 flush was higher than that in leaves in the later flush, except for herbivore-undamaged

351 seedlings in high-fertility soil, which showed no significant differences between flush

352 periods (Table 1). This indicates that the difference in CT concentration between flush

353 periods did not merely arise from leaf age. The difference in CT concentration between

354 flush periods could reflect contribution of different flushes to subsequent growth. For

355 example, Matsuki et al. (2004) showed that Betula platyphylla and B. ermanii invest highly in

356 defence in their early-season leaves, which make a major contribution to subsequent growth. In

contrast, B. maximowicziana invests its defences in late-season leaves, which are more

important to its growth (Matsuki et al. 2004). In case of successively flushing Quercus species,

359 leaves of the first and second shoots act as a carbon source during the production of

360 subsequent-flush shoot (Dickson et al. 2000). Therefore, leaves of the first shoots play a highly

361 important role in growth of subsequent-flush shoots (Alaoui-Sossé et al. 1996; Mizumachi et al.

362 2006). Our findings support this idea by showing that leaves of the first shoots, which would

363 contribute greatly to subsequent growth, had higher CT concentration (Table 1) and the effects 
364 of herbivore damage on leaf qualities were more clearly in leaves of the later shoots (Figs. 1-3).

366 higher than that of leaves in the second shoots, and the third and fourth shoots (Fig. 2). The

367 results are related to the seasonal variation in TP; concentrations of TP and hydrolyzable tannins,

368 which comprise the dominant group of phenolic compounds, are higher in younger oak leaves

369 (Rossiter et al. 1988; Mauffette and Oechel 1989; Salminen et al. 2004).

371 in CT and TP concentration in Q. serrata seedlings in low-fertility soil was greater than those in

372 high-fertility soil (Figs. 1-3) in accordance with several previous studies finding higher induced

373 response in low-fertility soil (Koricheva et al. 1998, Hunter and Schultz 1995; Ruohomäki et al.

374 1996; Hikosaka et al. 2005; Cornelissen and Stiling 2006; Koike et al. 2006). However leaf

375 damage observed in these flushes did not differ between low- and high-fertility soil (Fig. 5). In

376 the second flush, in contrast, leaf damage was higher in high-fertility soil than in low-fertility soil

377 (Fig. 5), while induced response did not differ between the different soil fertility levels (Figs.

378 1-3). Thus, the effect of soil fertility on leaf quality and leaf damage varied among flush stages.

379 These intriguing patterns may be understood in terms of that the timing of herbivory could 
380 influence induced responses. For example, during the elongation of the first flush, leaf damage

381 was caused mainly by the larvae of Lepidoptera, which feed on leaves before the leaves have

382 finished unfolding. While, during the elongation of the second flush, leaf damage was caused by

383 the adults of Coleoptera, which feed on leaves after the leaves have finished unfolding. The leaf

384 properties, such as CT and TP concentration and LMA, might be affected by at what stage of

385 leaf expansion did herbivory occur. Our experimental set-up in this study was such that the

386 sampling of all leaves was conducted at one time at the end of the growing season. Sequential

387 sampling in accordance with leaf expansion may allow us to examine whether the higher

388 induced defence observed in some treatments has the potential to protect the plants better against

389 subsequent insect damage.

390 We previously demonstrated that in high-fertility soil the probabilities of producing

391 subsequent shoots were higher (Mizumachi et al. 2006), and the number of shoots and total

392 shoot length produced in one growing season were greater (Mizumachi et al. 2004). It means

soil fertility affected not only the concentration of CT and TP in leaves, but also the growth

394 patterns of Q. serrata seedlings (Mizumachi et al. 2004, 2006). In low-fertility soil, the 
396 in high-fertility soil. In the present study, seedlings in low-fertility soil were better defended

397 against herbivore damage than those in high-fertility soil (Figs. 1-3). Taken together, these

398 results suggest that $Q$. serrata seedlings adjust the balance between induced response and

399 growth according to resource availability: seedlings in low-fertility soil have higher level of

400 induced response while showing relatively low potential for production of new photosynthetic

401 organs compared to those growing on more fertile soil.

In summary, this and our previous studies (Mizumachi et al. 2004, 2006) showed that $Q$.

serrata seedlings have the ability to produce later shoots and the ability to strengthen defensive

properties of leaves against herbivore damage. Furthermore, $Q$. serrata seedlings appear to

405 adjust the balance between these abilities according to resource availability. Given that

406 invertebrate herbivores prefer seedlings over older woody plants (Boege and Marquis 2005) and

407 that Q. serrata is host to 346 lepidopterans species (Teramoto 1996), the potential of $Q$.

408 serrata seedlings to adjust their physiological and morphological properties depending on

409 herbivory and soil fertility can be advantageous in forest floor where seedlings constantly are

410 exposed to herbivory. 
412 Acknowledgements We thank the members of the Kitashirakawa Experimental Station, Field

413 Science Education, and Research Center, Kyoto University, for their support in this experiment.

414 We also thank Professor H. Takeda, Mr. H. Ishii, and Dr. M. Yamasaki of Kyoto University for

415 their helpful advice and encouragement, and all of the members of the Laboratory of Forest

416 Ecology, Kyoto University, for engaging us in useful discussions. This study was supported in

417 part by a Grant-in-Aid for Science Research (No. 13306012, to N. Osawa) from the Ministry of

418 Education, Culture, Sports, Science, and Technology of Japan. This study was also supported by

419 Japan Society for the Promotion of Science (JSPS) Research Fellowships for Young

420 Scientists (No. $17 \cdot 2313$, to E. Mizumachi).

\section{References}

423

424 Alaoui-Sossé B, Ricaud S, Barnola P, Dizengremel P (1996) Rhythmic growth and carbon

425 allocation in Quercus robur. Sucrose metabolizing enzymes in leaves. Physiologia Plant

$426 \quad 96: 667-673$

427 Baraza E, Gómez JM, Hódar JA, Zamora R (2004) Herbivory has a greater impact in shade than 
428 in sun: response of Quercus pyrenaica seedlings to multifactorial environmental variation.

429 Can J Bot 82:357-364

430 Boege K (2004) Induced responses in three tropical dry forest plant species - direct and indirect effects on herbivory. Oikos 107:541-548

Boege K, Marquis RJ (2005) Facing herbivory as you grow up: the ontogeny of resistance in plants. Trends Ecol Evol 20:441-448

434 Borchert R (1975) Endogenous shoot growth rhythms and indeterminate shoot growth in oak. Physiol Plant 35:152-157

436 Chaar H, Colin F, Collet C (1997a) Effects of environmental factors on the shoot development of Quercus petraea seedlings -A methodological approach. For Ecol Manage 97:119-131

438 Chaar H, Colin F, Leborgne G (1997b) Artificial defoliation, decapitation of the terminal bud,

439 and removal of the apical tip of the shoot in sessile oak seedlings and consequences on

$440 \quad$ subsequent growth. Can J For Res 27:1614-1621

441 Choong MF (1996) What makes a leaf tough and how this affects the pattern of Castanopsis fissa leaf consumption by caterpillars. Funct Ecol 10:668-674

443 Coley PD (1983) Herbivory and defensive characteristics of tree species in a lowland tropical 
445 Cornelissen T, Stiling P (2006) Does low nutritional quality act as a plant defence? An

446 experimental test of the slow-growth, high-mortality hypothesis. Ecol Entomol 31:32-40

447 Dickson RE, Tomlinson PT, Isebrands JG (2000) Allocation of current photosynthate and

448 changes in tissue dry weight within northern red oak seedlings: individual leaf and flush

449 carbon contribution during episodic growth. Can J For Res 30:1296-1307

450 Feeny P (1970) Seasonal changes in oak leaf tannins and nutrients as a cause of spring feeding by winter moth caterpillars. Ecology 51: 565-581

452 Forkner RE, Hunter MD (2000) What goes up must come down? Nutrient addition and predation pressure on oak herbivores. Ecology 81:1588-1600

454 Forkner RE, Marquis RJ (2004) Uneven-aged and even-aged logging alter foliar phenolics of oak trees remaining in forested habitat matrix. For Ecol Manage 199:21-37

456 Forkner RE, Marquis RJ, Lill JT (2004) Feeny revisited: condensed tannins as anti-herbivore

458 Furuno T, Saito H (1981) Seasonal variations of litter fall and primary consumption by 
$460 \quad 53: 52-64$

461 Hanley ME, Lamont BB, Fairbanks MM, Rafferty CM (2007) Plant structural traits and their

462 role in anti-herbivore defence. Perspectives in Plant Ecol, Evol and Systematics 8:157-178

463 Haukioja E (1990) Induction of defenses in trees. Annu Rev Entomol 36:25-42

464 Hikosaka K, Takashima T, Kabeya D, Hirose T, Kamata N (2005) Biomass allocation and leaf

465 chemical defence in defoliated seedlings of Quercus serrata with respect to carbon-nitrogen

466 balance. Ann Bot 95:1025-1032

467 Hunter MD (1987) Opposing effects of spring defoliation on late season oak caterpillars. Ecol

$468 \quad$ Entomol 12:373-382

469 Hunter MD, Schultz JC (1995) Fertilization mitigates chemical induction and herbivore

$470 \quad$ responses within damaged oak trees. Ecology 76:1226-1232

471 Karban R, Baldwin IT (1997) Induced responses to herbivory. The University of Chicago Press,

472 Chicago, IL

473 Karban R, Myers JH (1989) Induced plant responses to herbivory. Annu Rev Ecol Syst

475 Koike T, Tobita H, Shibta T, Matsuki S, Konno K, Kitao M, Yamashita N, Maruyama Y (2006) 
476 Defense characteristics of seral deciduous broad-leaved tree seedlings grown under differing

477 levels of $\mathrm{CO}_{2}$ and nitrogen. Popul Ecol 48:23-29

478 Koricheva J, Larsson S, Haukioja E, Keinänen M (1998) Regulation of woody plant secondary

479 metabolism by resource availability: hypothesis testing by means of meta-analysis. Oikos

$480 \quad 83: 212-226$

481 Kudo G (1996) Herbivory pattern and induced responses to simulated herbivory in Quercus mongolica var. grosseserrata. Ecol Res 11:283-289

Kytö M, Niemelä P, Larsson S (1996) Insects on trees: population and individual response to fertilization. Oikos 75:148-159

485 Lill JT, Marquis RJ (2001) The effects of leaf quality on herbivore performance and attack from natural enemies. Oecologia 126:418-428

Lower SS, Kirshenbaum S, Orians CM (2003) Preference and performance of a willow-feeding leaf beetle: soil nutrient and flooding effects on host quality. Oecologia 136: 402-411

491 Mattson WJ (1980) Herbivory in relation to plant nitrogen content. Annu Rev Ecol Syst 
Mauffette Y, Oechel WC (1989) Seasonal variation in leaf chemistry of the coast live oak Quercus agrifolia and implications for the California oak moth Phryganidia californica. Oecologia 79:439-445

Migita C, Chiba Y, Tange T (2007) Seasonal and spatial variations in leaf nitrogen content and resorption in a Quercus serrata canopy. Tree Physiol 27:63-70

Mizumachi E, Mori A, Osawa N, Akiyama R, Tokuchi N (2006) Shoot development and extension of Quercus serrata saplings in response to insect damage and nutrient conditions. Ann Bot 98:219-226 fertility on the growth patterns of Quercus serrata and Q. crispula saplings at the shoot and individual levels. Popul Ecol 46:203-211 larval assemblages associated with oak, Quercus crispula: the importance of leaf quality.

507 Mutikainen P, Walls M, Ovaska J, Keinänen M, Julkunen-Tiitto R, Vapaavuori E (2000) 
508 Herbivore resistance in Betula pendula: effect of fertilization, defoliation, and plant

509 genotype. Ecology 81:49-65

510 Nabeshima E, Murakami M, Hiura T (2001) Effects of herbivory and light conditions on

511 induced defense in Quercus crispula. J Plant Res 114:403-409

512 Nakamura M, Hina T, Nabeshima E, Hiura T (2008) Do spatial variation in leaf traits and

513 herbivory within a canopy respond to selective cutting and fertilization? Can J For Res

$514 \quad 38: 1603-1610$

515 Nomura M, Itioka T (2002) Effects of synthesized tannin on the growth and survival of a

516 generalist herbivorous insect, the common cutworm, Spodoptera litura Fabricius

517 (Lepidoptera: Noctuidae). Appl Entomol Zool 37:285-289

518 Nykänen H, Koricheva J (2004) Damage-induced changes in woody plants and their effects on

519 insect herbivore performance: a meta-analysis. Oikos 104:247-268

520 Ohsawa T, Saito Y, Sawada H, Ide Y (2008) Impact of altitude and topography on the genetic

521 diversity of Quercus serrata populations in the Chichibu Mountains, central Japan. Flora 203:187-196

523 Ozawa H, Itoh K, Hori Y (2000) Shoot structure and dynamics of saplings and canopies of three 
524 deciduous broad-leaved trees of a coppice forest in central Japan. Trees 14:206-214

525 Poorter H, Niinemets U, Poorter L, Wright IJ, Villar R (2009) Causes and consequences of

526 variation in leaf mass per area (LMA): a meta-analysis. New Phytologist 182:565-588.

527 Porter LJ, Hrstich LN, Chan BG (1986) The conversion of procyanidins and prodelphinidins to cyanidin and delphinidin. Phytochemistry 25:223-230

529 Reich PB, Uhl C, Walters MB, Elsworth DS (1991) Leaf lifespan as a determinant of leaf $530 \quad$ structure and function among 23 amazonian tree species. Oecologia 86:16-24

531 Rossiter MC, Schultz JC, Baldwin IT (1988) Relationships among defoliation, red oak phenolics, and gypsy moth growth and reproduction. Ecology 69:267-277

533 Ruohomäki K, Chapin III FS, Haukioja E, Neuvonen S, Suomela J (1996) Delayed inducible

534 resistance in mountain birch in response to fertilization and shade. Ecology 77:2302-2311

535 Salminen J-P, Roslin T, Karonen M, Sinkkonen J, Pihlaja K, Pulkkinen P (2004) Seasonal

536 variation in the content of hydrolyzable tannins, flavonoid glycosides, and

537 proanthocyanidins in oak leaves. J Chem Ecol 30:1693-1711

538 SAS Institute (2005) JMP Statistical Discovery Software (ver. 6.0). SAS Institute Inc, Cary, NC

539 Southwood TRE (1961) The number of species of insect associated with various trees. J Anim 
$540 \quad$ Ecol 30:1-8

541 Sprugel DG, Hinckley TM, Schaap W (1991) The theory and practice of branch autonomy.

$542 \quad$ Annu Rev Ecol Syst 22:309-334

543 Stamp N (2003) Out of the quagmire of plant defense hypotheses. Q Rev Biol 78:23-55

544 Teramoto N (1993) Catalogue of host plants of lepidopterous insects in Japan (Fagaceae) (in

$545 \quad$ Japanese). Bull Shiga Agric Exp Stn [Extra issue] 1:1-161

546 Teramoto N (1996) Studies on lepidopterous insect fauna on Fagaceous plants, as the food

547 plants of the wild silk moth, Antheraea yamamai (in Japanese). Special Bull Shiga Agric

$548 \quad$ Exp Stn 19:1-216

549 Wait DA, Jones CG, Coleman JS (1998) Effects of nitrogen fertilization on leaf chemistry and

550 beetle feeding are mediated by leaf development. Oikos 82: 502-514

551 Waterman PG, Mole S (1994) Analysis of phenolic plant metabolites. Blackwell Science

552 Publications, London

553 Watson MA (1986) Integrated physiological units in plants. Trends Ecol Evol 1:119-123

554 White J (1979) The plant as a metapopulation. Annu Rev Ecol Syst 10:109-145

555 Wold EN, Marquis RJ (1997) Induced defense in white oak: effects on herbivores and 
557 Yamasaki M, Kikuzawa K (2003) Temporal and spatial variations in leaf herbivory within a

558 canopy of Fagus crenata. Oecologia 137:226-232

559

560 
560 Fig. 1 Condensed tannin (CT) concentration (means \pm s.e.) in leaves of shoots produced at each flush stage in Quercus serrata seedlings in treatments of herbivory and soil fertility.

564 Fig. 2 Total phenolics (TP) concentration (means \pm s.e.) in leaves of shoots produced at each flush stage in Quercus serrata seedlings in treatments of herbivory and soil fertility.

Fig. 3 Leaf mass per area (LMA; means \pm s.e.) in leaves of shoots produced at each flush stage in Quercus serrata seedlings in treatments of herbivory and soil fertility. Different letters are significantly different by Tukey's HSD test $(P<0.05)$.

Fig. 4 Nitrogen $(\mathrm{N})$ concentration (means \pm s.e.) in leaves of shoots produced at each fertility. 
576 Fig. 5 Leaf damage class (means \pm s.e.) of shoots produced at each flush stage in Quercus serrata seedlings in treatments of soil fertility. 


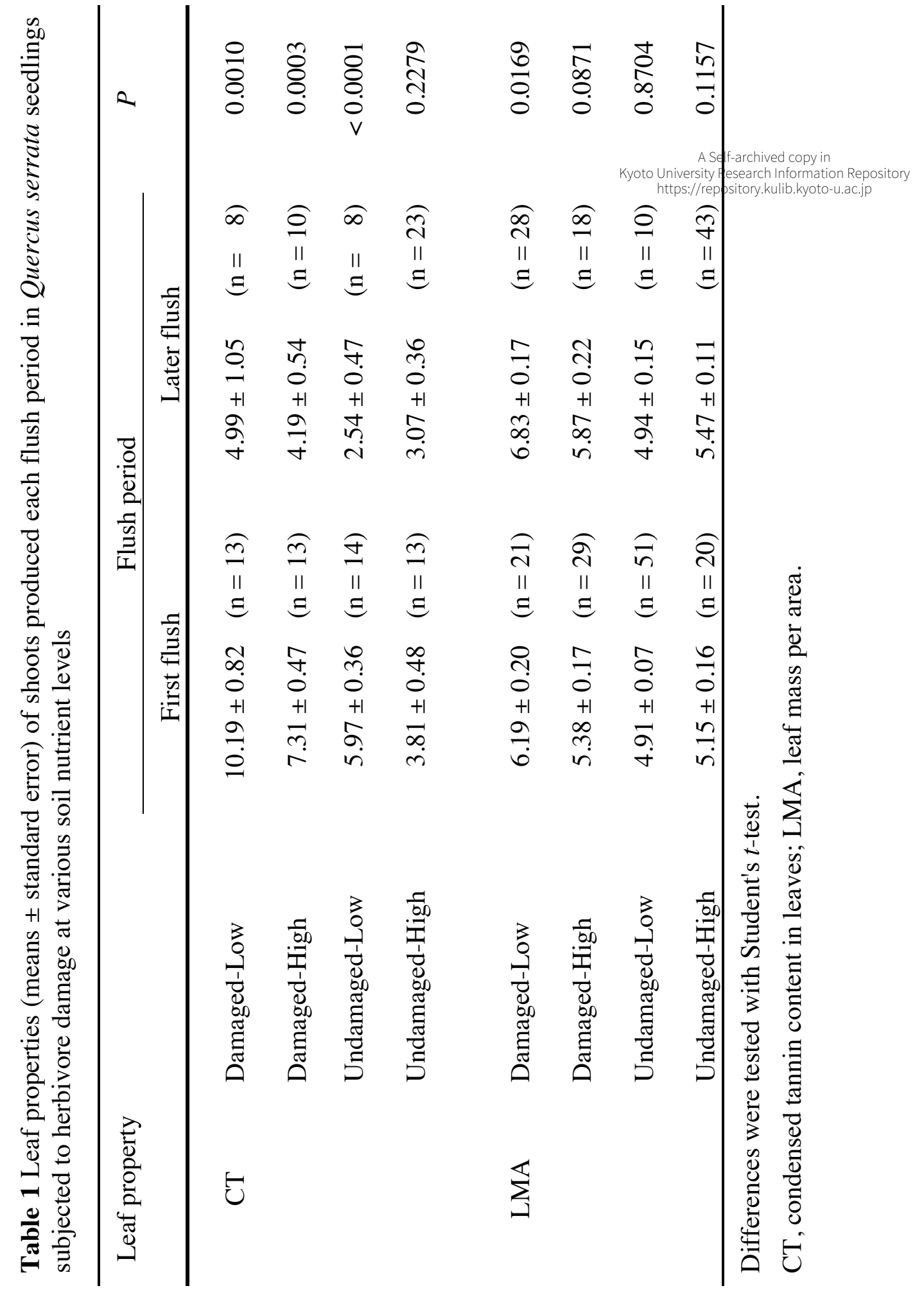


Fig. 1

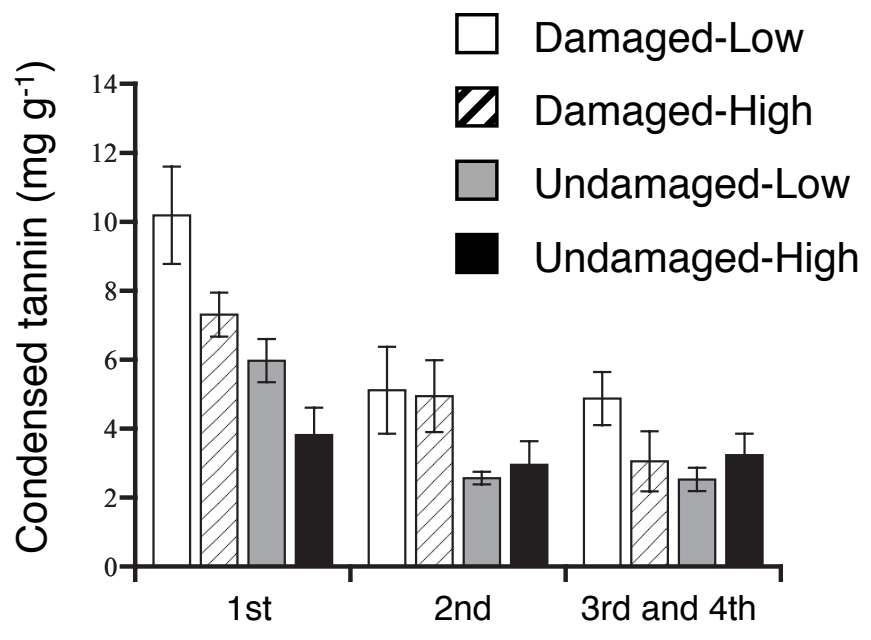

Flush stage 
Fig. 2

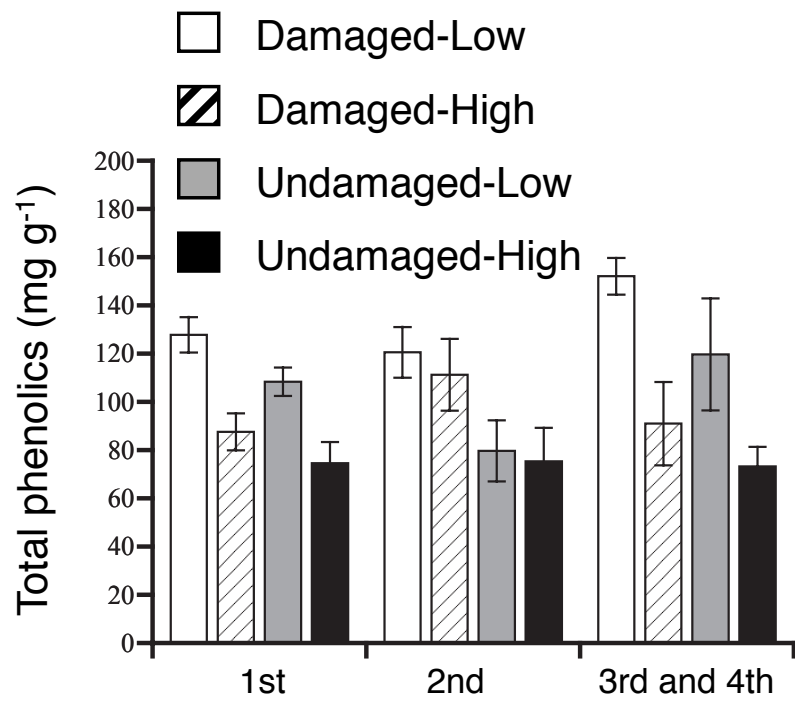

Flush stage 
Fig. 3

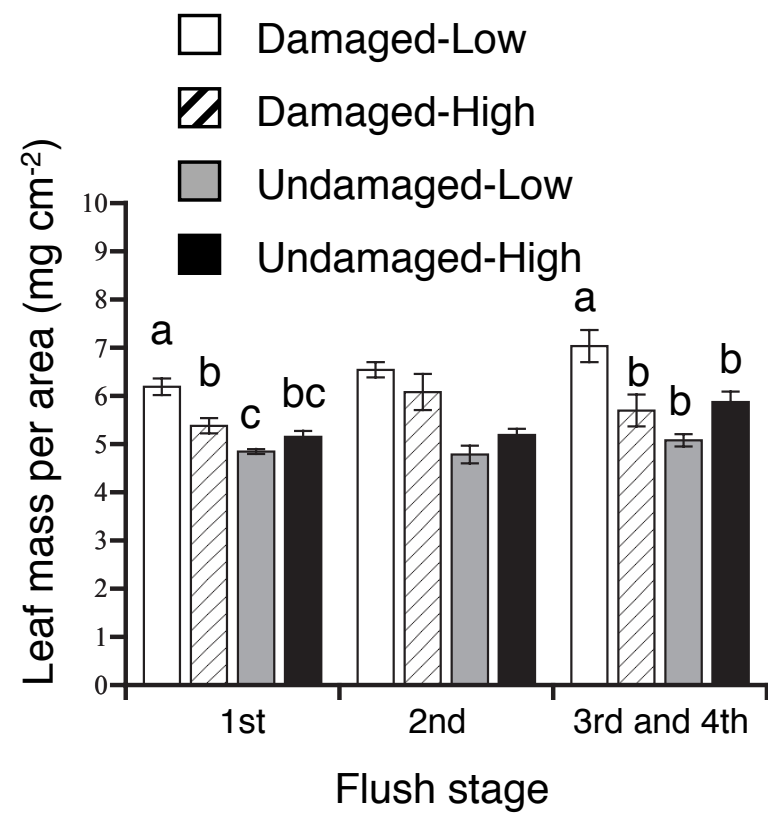


Fig. 4

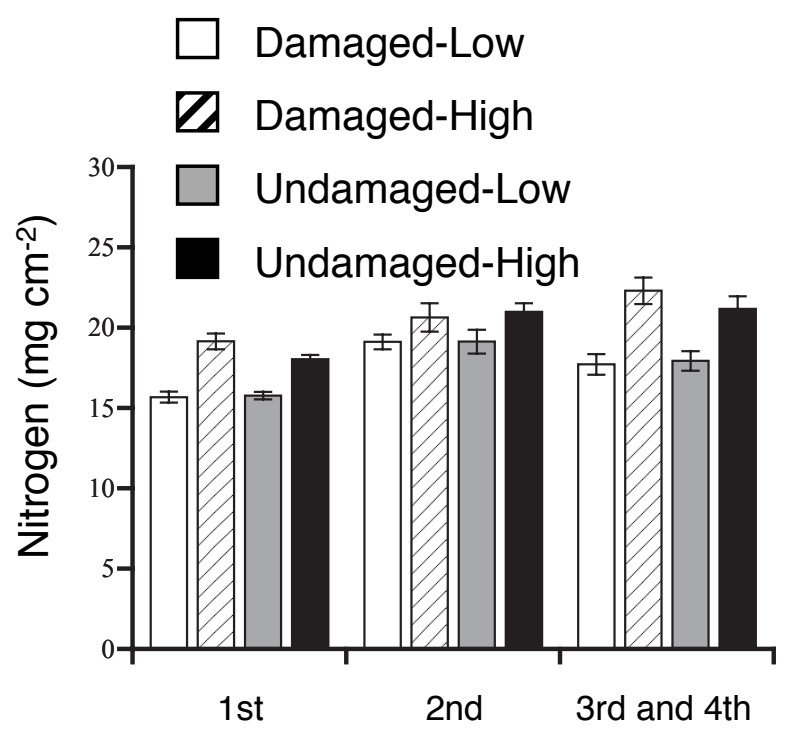

Flush stage 
Fig. 5

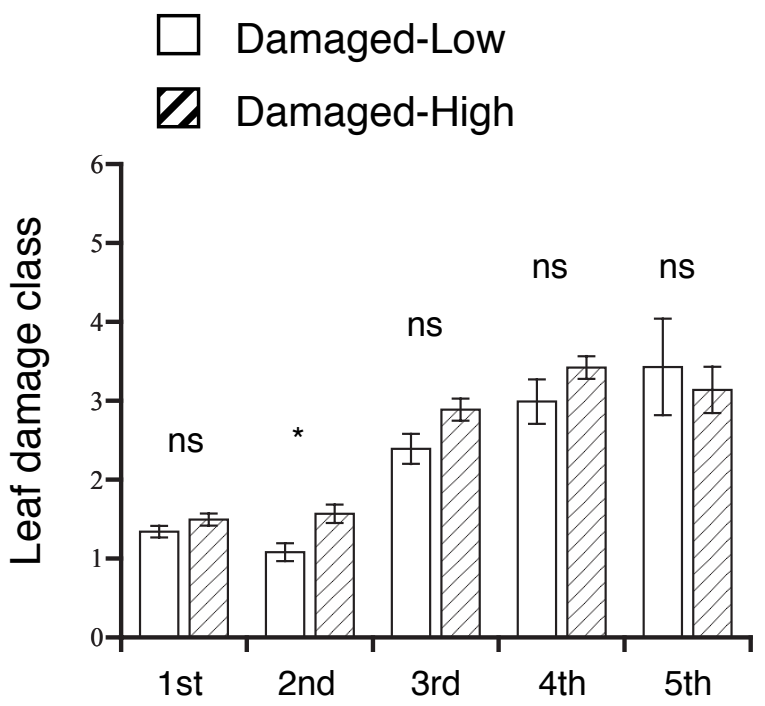

Flush stage 